\title{
CORRELATIVE OBSERVATIONS ON CEREBRAL METABOLISM AND CARDIAC OUTPUT IN MYXEDEMA ${ }^{1}$
}

\author{
By P. SCHEINBERG, ${ }^{2}$ E. A. STEAD, JR., E. S. BRANNON, AND J. V. WARREN \\ (From the Department of Medicine, Duke University School of Medicine, Durham, North Caro- \\ lina, and Department of Medicine, Emory University School of Medicine, \\ Atlanta, Georgia)
}

(Submitted for publication March 31, 1950; accepted, May 29, 1950)

Patients with myxedema present an unusual opportunity for studying the effect of lowered metabolism on organ blood flow and for observing the effect of changes in peripheral circulation on cardiac output. Studies of cerebral metabolism in myxedema are of interest to the physician because changes in cerebral metabolism may be of importance in understanding the alterations in mental status which occur with this disease (1-3). The cerebral blood flow was measured by the nitrous oxide method of Kety and Schmidt (4) in eight patients with myxedema. The cardiac output was measured by the technique of right atrial catheterization in seven other patients with myxedema.

\section{METHOD}

The diagnosis of myxedema was a clinical one, depending upon the history and physical findings, and supported by laboratory data. The basal metabolic rates were abnormally low and the serum cholesterol levels abnormally high in all of the patients. The right atrial pressure was increased in one patient (P. B., Table I). No attempt was made to evaluate the mental status of the patients in whom the cardiac output was measured. Complete mental status examinations, with particular attention to level of awareness, were performed on all the subjects in the cerebral blood flow group. These were arbitrarily graded from $1+$, indicating personality changes, memory defects, and inability to concentrate, to $3+$, which indicated disorientation and confusion. One of the patients (M. M., Table II) was frankly psychotic, with delusions and hallucinations. Neither she nor E. M. remembered their previous studies when they returned for re-examination. Electroencephalograms were done on five of the patients on whom cerebral blood flow was measured.

Cardiac output was measured by the method of right heart catheterization utilizing the direct Fick principle $(5,6)$. The samples of mixed venous blood were taken from the right atrium, and the femoral arterial pressure

1 This work was supported by the Life Insurance Medical Research Fund.

2 Fellow, American Heart Association. Present address : University of Miami Medical Research Unit, Veterans Administration Hospital, Coral Gables, Fla. was recorded with a Hamilton manometer. The nitrous oxide technique for measuring cerebral blood flow has been previously described (4), and the modification in use in this laboratory of collecting simultaneous, continuous samples from the artery and internal jugular bulb, rather than five separate arterial and venous samples, has been reported elsewhere, together with our normal values (7). In the cerebral metabolism study, blood oxygen content was measured by the spectrophotometric method of Hickam and Frayser (8) ; in the cardiac output study, it was measured by the manometric method of Van Slyke (9). Blood glucose content was measured by Nelson's modification of Somogyi's method (10); in most instances, each arterial cerebral venous glucose difference represents an average of four such arteriovenous differences drawn during the procedure. The calculation of cerebral oxygen consumption, cerebral glucose consumption, and cerebral vascular resistance has been previously described $(4,7)$. Cerebral venous oxygen tension was not measured directly, but computed from the per cent oxygen saturation of the cerebral venous blood using a standard oxyhemoglobin dissociation curve drawn for $\mathrm{pH}$ 7.4. Mean arterial pressures in the cerebral metabolism study were calculated from the formula MP $=$ diastolic pressure plus $\frac{\text { pulse pressure }}{3}$, the readings being obtained at one minute intervals by the standard auscultation procedure with the arm held at heart level.

\section{RESULTS}

Cardiac output. The essential data are presented in detail in Table I. The patients with myxedema were compared with a group of normal subjects studied under the same laboratory circumstances (11). The mean decrease in cardiac index from normal was 47 per cent, and the mean decrease in total oxygen consumption was 37 per cent. There was an excellent correlation between cardiac index and basal metabolic rate, the correlation coefficient $(r)$ being 0.90 . The apparent moderate increase in mixed arterial-venous oxygen difference proved not to be statistically significant. The two patients who were restudied after treatment showed sizable increases in both cardiac index and total oxygen consumption. 
Cerebral metabolic functions. The essential data are given in detail in Table II. There was a 38 per cent decrease from normal in mean cerebral blood flow, a 27 per cent decrease from normal in mean cerebral oxygen consumption, a 26 per cent decrease in mean cerebral glucose consumption, and a 91 per cent increase over normal in cerebral vascular resistance. The mean $\frac{\mathrm{A}-\mathrm{V} \text { glucose }}{\mathrm{A}-\mathrm{V} \text { oxygen }}$ ratio was normal, indicating that the brain continues to use glucose as its primary food substance in myxedema. Although insufficient data were available for statistical comparison, the mean cerebral venous oxygen tension appeared to be abnormally low.

The correlations between various measured functions are of considerable interest. There was an excellent correlation between basal metabolic rate and cerebral blood flow $(r=0.86)$, but only a fair degree of correlation between BMR and the extent of mental status alteration $(r=0.65)$ and between BMR and cerebral oxygen consumption $(r=0.63)$. There was also a high degree of correlation between cerebral blood flow and cerebral oxygen consumption $(r=0.81)$. There was only a rough correlation between mental status defects and cerebral oxygen consumption $(r=0.59)$, but in view of the difficulty inherent in grading mental status defects, this was considered to show a definite relationship between these two functions. There is apparently no relationship in myxedema between oxygen tension of cerebral venous blood and cerebral oxygen consumption or mental status defects, the $r$ values being 0.32 and 0.39 , respectively.

The three patients who were restudied following thyroid therapy showed a definite return toward normal in all their cerebral metabolic functions. The cerebral blood flow increased 116 per cent, 40 per cent, and 45 per cent, respectively, and cerebral oxygen and glucose consumptions increased in like manner. There was no consistent change

TABLE I

The cardiac output in seven patients with myxedema

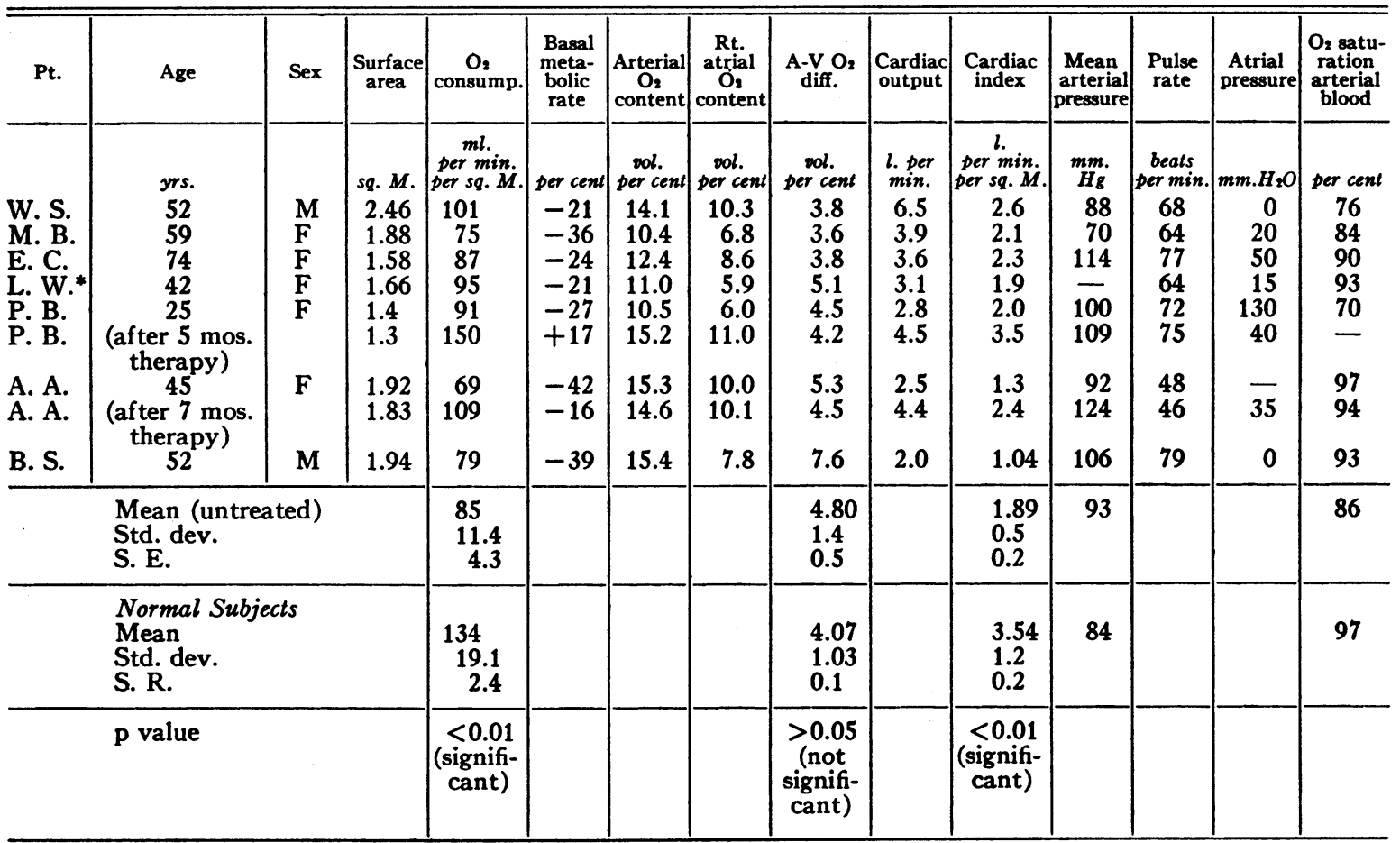

Std. dev. $=$ Standard deviation $=S=\sqrt{\frac{S X^{2}-\frac{(S X)^{2}}{n}}{n-1}}$

S.E. $=$ Standard error $=S / \sqrt{\mathbf{n}}$.

* Arterial pressure by auscultatory method was $100 / 70$. 
TABLE II

Cerebral metabolic functions in myxedema

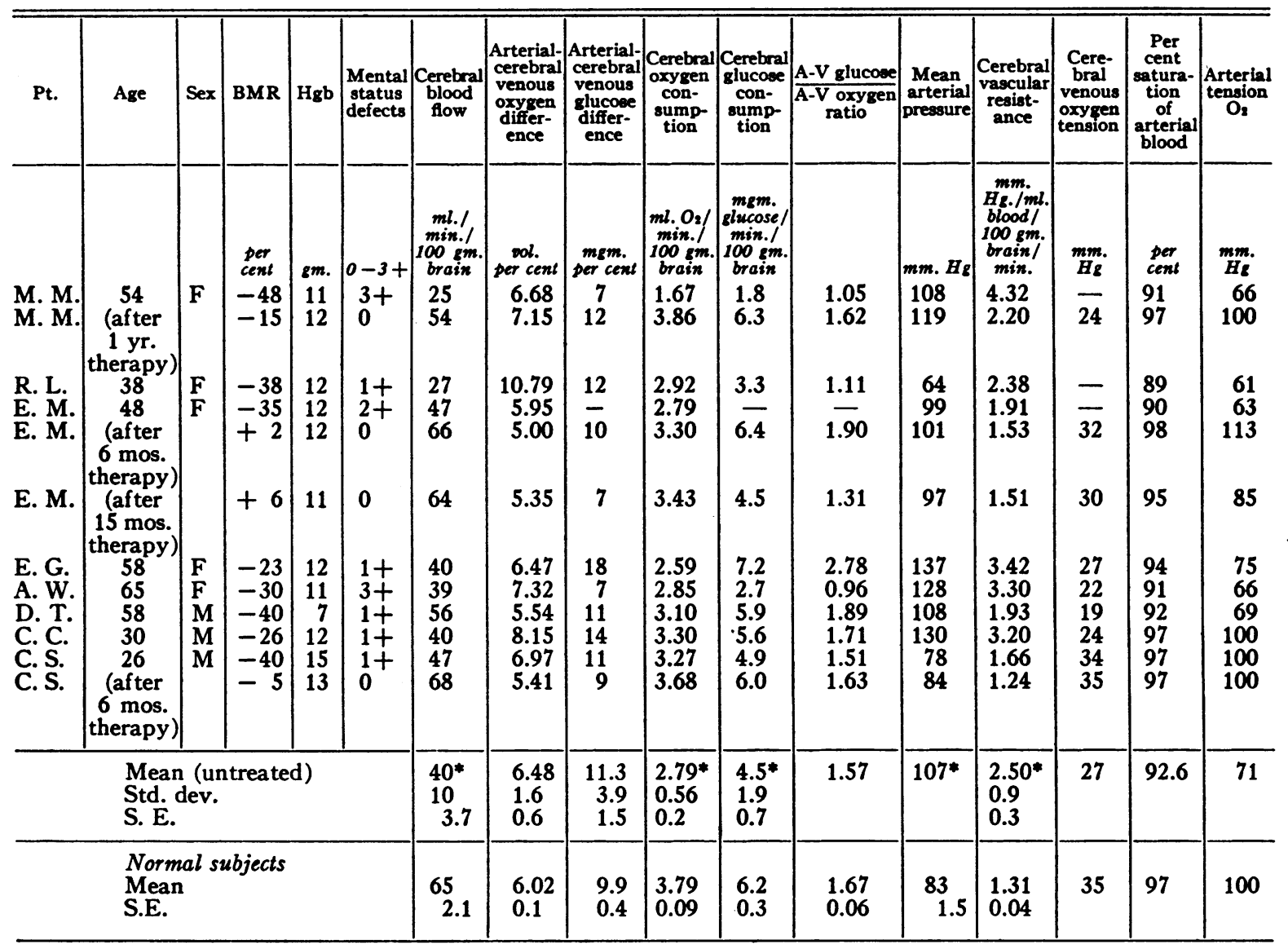

* Indicates significant deviation from normal. All $\mathrm{p}$ values $<0.01$.

Std. dev. = Standard deviation $=S=\sqrt{\frac{S X^{2}-\frac{(S X)^{2}}{n}}{n-1}}$.

S.E. $=$ Standard error $=S / \sqrt{\mathbf{n}}$.

in the arterial-cerebral venous oxygen and glucose differences, but in all three instances, cerebral vascular resistance was strikingly reduced from the original study. In the one patient (E. M.) who was studied on three occasions, there was no difference in the results obtained after six and 15 months of treatment. In all three patients, improvement in cerebral metabolic function paralleled clinical improvement in appearance, general wellbeing, mental status, and basal metabolic rate.

Electroencephalograms. Previous investigators have shown that the electroencephalogram in myxedema typically shows low voltage, with a slow frequency pattern, a lack of alpha waves, and absence of reaction to light stimulus (12). Four of the five patients on whom electroencephalograms were recorded in this study showed one or more of the above characteristics, but no consistent type of tracing was noted. E. M. had a low voltage record $(10-12 \mu \mathrm{V})$ with poorly and rarely developed alpha pattern, with no response to over-ventilation. Following thyroid therapy, her tracings showed an increase in the amplitude of all waves (40-50 $\mu \mathrm{V}$ ) and the development of a seven per second frequency pattern, which was dominant but mixed with faster and slower forms (Figure 1). A. W. also had a low voltage record $(10-15 \mu \mathrm{V})$ with a poorly developed alpha pattern and no response to over-ventilation. No subsequent observations have been made on this patient. The tracing of 


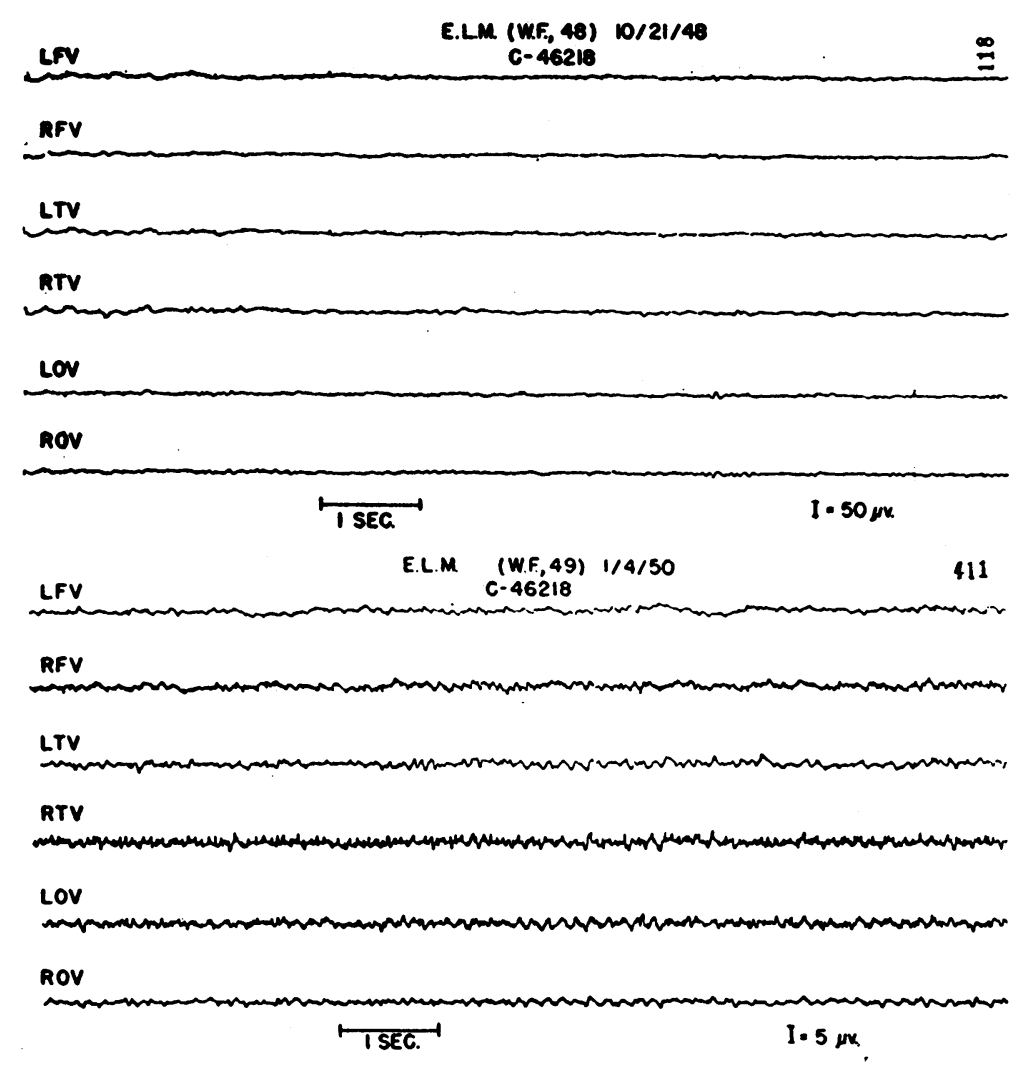

Fig. 1. Changes in Electroencephalogram following 15 Months' THYROID THERAPY

Upper tracing was made prior to treatment.

patient E. G. showed no dominant frequency pattern, but many waves of varying form and shifting frequency, and moderately low voltage (15-40 $\mu \mathrm{V})$. Following therapy, the voltage of the entire tracing increased $(35-110 \mu \mathrm{V})$, but the frequency and wave form characteristics remained the same (Figure 2). Patient D. T. showed a seven per second frequency pattern with a relatively low voltage $(25 \mu \mathrm{V})$; no observations were made during therapy. Patient C. S. had a normal tracing; it is interesting that this patient also had the least reduction in measured cerebral metabolism.

Arterial oxygen saturation. In patients in Table I, per cent oxygen saturation of arterial blood was measured in a routine manner. No attempt was made to detect minor variations from normal. In at least four of the eight patients studied, the arterial blood was not normally saturated. In patients in Table II, the per cent saturation of arterial hemoglobin was measured with consider- able care by the spectrophotometric technique. In this group, the mean measured arterial oxygen saturation of the hemoglobin was 93 per cent, and the mean calculated arterial oxygen tension was $71 \mathrm{~mm}$. Hg. The values for normal controls are 97 per cent and $100 \mathrm{~mm}$. $\mathrm{Hg}$, respectively. The arterial oxygen unsaturation noted here may be caused by inadequate pulmonary ventilation or by changes in the alveoli or capillaries, but further studies are needed to elucidate this question. It is of interest that in patients M. M. and E. M. of Table II, the arterial oxygen saturation became normal following thyroid treatment.

\section{DISCUSSION}

It should be re-emphasized that, although the two groups of patients reported here were not studied together, the obvious similarities in the size of the groups, severity of the disease, and age of the patients seemed to render them suitable for profitable comparison. The fact that the average 
age of the patients in both groups is considerably greater than that of the normal subjects with which they are compared must be kept in mind. There is some indication that the cardiac output falls with advancing age (13). The effect of age on cerebral blood flow has not been determined. In a series of patients who had hypertension or generalized vascular disease without change in mental status and who were similar in age to the patients with myxedema, a moderate reduction in blood flow occurred without any change in oxygen and glucose consumption (14). In our opinion, the magnitude of the changes in both cardiac output and cerebral metabolism presented in this paper are far greater than can be explained on the basis of age alone.

The decrease in cardiac output recorded in this series is particularly striking because of the fact that in three subjects, both anemia and arterial oxygen unsaturation of a considerable degree were present. These factors tend to complicate the interpretation of the mixed arteriovenous oxygen differences. The slow skin blood flow which occurs in myxedema $(15,16)$ would be expected to increase the mixed arteriovenous oxygen difference, while anemia and arterial unsaturation would lower it. The value for mixed arteriovenous oxygen difference is of considerable importance in determining whether heart failure is present in a patient without any complicating disturbances. When the output is below the needs of the tissues, the arteriovenous oxygen difference widens. In myxedema, a situation in which tissue metabolism is lowered, the cardiac output is decreased and the arteriovenous oxygen difference is normal. This suggests a lessened demand of the tissues for blood rather than cardiac failure. The finding of a normal arterial-internal jugular oxygen difference with a reduced cerebral blood flow is compatible with this interpretation. Before this interpretation can be completely accepted, studies must be done on patients with myxedema during exer-

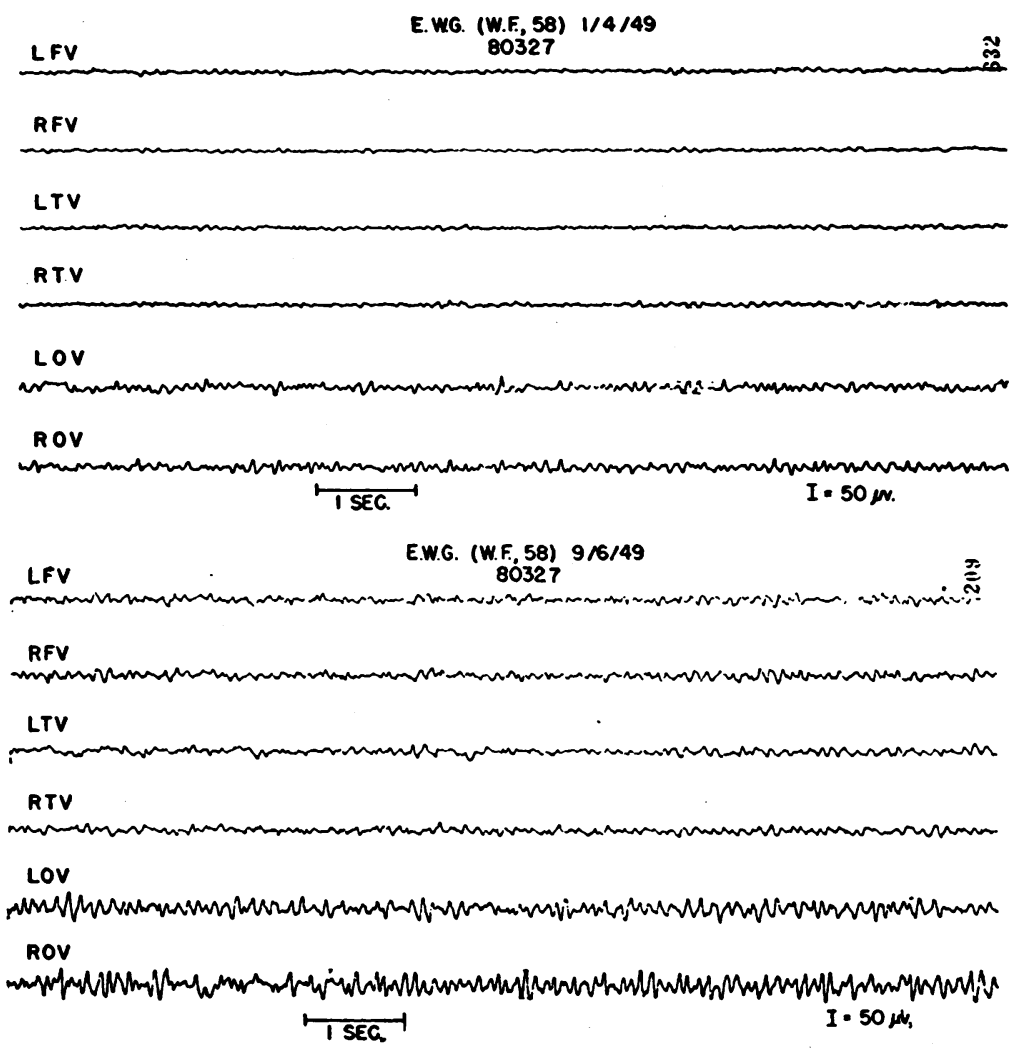

Fig. 2. Changes in Electroencephalogram following Eight Months' THYROID THERAPY

Upper tracing was made prior to therapy. 
cise to show that the heart can respond to peripheral stimuli.

In patient $\mathrm{P}$. B., the right atrial pressure was elevated and the heart was enlarged strikingly. This subject had either congestive failure or pericardial tamponade from a massive pericardial effusion. The relatively normal mixed arteriovenous oxygen difference suggests pericardial tamponade sufficient to increase the atrial and venous pressures without decreasing the cardiac output as the cause of the rise in right atrial pressure. The right atrial pressure in the other five patients in whom it was measured was within normal limits.

The finding of a low cardiac output per square meter of body surface with a normal or elevated mean arterial pressure indicates that the total vascular resistance of the body is increased. The mechanisms by which hypothyroidism causes this increase in peripheral resistance are not known.

The decrease in cerebral blood flow and the increase in cerebral vascular resistance in the patients with myxedema cannot be attributed solely to the presence of vascular disease because in the three patients studied after treatment, the blood flow increased and the vascular resistance fell. Furthermore the increase in vascular resistance in the untreated patients was greatly in excess of that seen in uncomplicated hypertension of this degree. One might speculate that the increase in cerebral vascular resistance is secondary to the reduction in cerebral metabolism produced by myxedema; this would be consistent with the excellent correlation $(r=0.76)$ between these two functions shown in these data. A survey of the known relations between arterial pressure, cerebral vascular resistance, and cerebral metabolism shows that there is no simple relation between cerebral metabolism and cerebral vascular resistance.

An increase in cerebral vascular resistance is seen in patients with hypertension (17), cerebral arteriosclerosis (14), congestive heart failure (18), pernicious anemia after.treatment (19), and in normal subjects during hyperventilation (20) and barbiturate anesthesia $(21,22)$. The mechanisms by which these changes in resistance are accomplished have not been elucidated. Certainly some of these mechanisms are reversible. Simple reduction in cerebral blood flow as a result of de- creasing the effective cerebral arterial pressure does not increase the cerebral vascular resistance. This is shown by the observations on motionless standing in normal subjects (7). That a reversible increase in resistance is not determined solely by the rate of cerebral metabolism is shown by the high resistance in normal subjects during hyperventilation and in patients with heart failure in whom the cerebral metabolism is normal. Cerebral metabolism is decreased in proportion to the reduction of cerebral blood flow in patients with vascular disease with changes in mental status (14), in certain patients with pernicious anemia (19), and in patients with myxedema. On the other hand, cerebral blood flow is increased out of proportion to cerebral metabolism in patients inhaling 5 to 7 per cent $\mathrm{CO}_{2}$ (23), and is unchanged in the presence of marked reduction in cerebral metabolism in patients with insulin hypoglycemia (24).

The decreased cerebral oxygen and glucose metabolism in myxedema appears to result from deficiency of thyroid hormone, under which circumstances the brain cells apparently do not extract sufficient quantities of oxygen and glucose from the blood. These findings are compatible with the mental and electroencephalographic changes observed in myxedema and the rough correlation demonstrated here between the degree of mental status impairment and cerebral oxygen consumption. No correlation was discernible between duration of illness and mental status or duration of illness and cerebral oxygen consumption.

The data from this study are compatible with the interpretation that the reduction in cardiac out-

TABLE III

Percentage alterations of cardiac index and total oxygen consumption as compared to cerebral blood flow and cerebral oxygen consumption in myxedema (mean values)

\begin{tabular}{l|c|c|c}
\hline \hline & Normal & Myxedema & $\begin{array}{c}\text { Per cent } \\
\text { change }\end{array}$ \\
\hline $\begin{array}{l}\text { Cardiac Index } \\
(l . / \text { min./sq.M.) }\end{array}$ & 3.54 & 1.89 & -47 \\
$\begin{array}{l}\text { Cerebral blood flow } \\
\text { (ml./min./100 gm. brain) }\end{array}$ & 65 & 40 & -38 \\
$\begin{array}{l}\text { Total } \mathrm{O}_{2} \text { Consumption } \\
\text { (ml. } \mathrm{O}_{2} / \text { min./sq.M.) }\end{array}$ & 134 & 85 & -35 \\
$\begin{array}{l}\text { Cerebral } \mathrm{O}_{2} \text { Consumption } \\
\left(\text { ml. } \mathrm{O}_{2} / \text { min./100 gm. brain) }\right.\end{array}$ & 3.79 & 2.79 & -27 \\
\hline
\end{tabular}


put is secondary to a generalized reduction in organ blood flow (Table III). The mechanisms by which cerebral vascular resistance is increased and organ blood flow reduced, and the mechanisms by which the output of the heart is decreased are not clarified.

\section{SUMMARY}

1. Cardiac output was measured by the direct Fick method on seven patients with myxedema, and cerebral blood flow and metabolism was measured by the nitrous oxide technique on eight other patients with myxedema.

2. Cardiac output was reduced 47 per cent from normal, and returned toward normal in two patients restudied during thyroid therapy.

3. Cerebral blood flow was reduced 38 per cent and cerebral oxygen and glucose consumption 27 per cent, respectively, from normal ; cerebral vascular resistance was increased 91 per cent. All cerebral metabolic values returned toward normal in the three patients restudied during thyroid therapy.

4. Electroencephalographic patterns previously noted in myxedema were observed in this study, and alterations in the pattern occurred during thyroid therapy.

5. The mean arterial oxygen saturation is decreased in myxedema.

6. The data are compatible with the interpretation that the mental changes in myxedema are the result of decreased cerebral oxygen and glucose metabolism and that the reduction in cardiac output is secondary to a generalized reduction in organ blood flow. The relationships between cerebral vascular resistance and cerebral metabolism are discussed.

\section{ACKNOWLEDGMENTS}

The authors are grateful to Dr. Irving Pine, Duke Hospital, for his assistance in obtaining and interpreting the electroencephalograms. This study was done with the technical assistance of Miss Frances Morgan, Miss Dorothy Frederick, Mrs. Louise Allen, Miss Eloise Cavin, and Miss Maurine Giese.

\section{BIBLIOGRAPHY}

1. Asher, R., Myxedoematous madness. Brit. M. J., 1949, 2, 555.

2. Zondek, H., and Wolfsohn, G., Myxedema and psychosis. Lancet, 1944, 2, 438.
3. Uyematsu, S., A case of myxedematous psychosis. Clinical and pathological report. Arch. Neurol. \& Psychiat., 1920, 3, 252.

4. Kety, S. S., and Schmidt, C. F., The nitrous oxide method for the quantitative determination of cerebral blood flow in man: theory, procedure, and normal values. J. Clin. Invest., 1948, 27, 476.

5. Cournand, A., and Ranges, H. A., Catheterization of the right auricle in man. Proc. Soc. Exper. Biol. \& Med., 1941, 46, 462.

6. Stead, E. A., Jr., Warren, J. V., Merrill, A. J., and Brannon, E. S., The cardiac output in male subjects as measured by the technique of right atrial catheterization. Normal values with observations on the effect of anxiety and tilting. J. Clin. Invest., $1945,24,326$.

7. Scheinberg, P., and Stead, E. A., Jr., The cerebral blood flow in male subjects as measured by the nitrous oxide technique. Normal values for blood flow, oxygen utilization, glucose utilization, and peripheral resistance, with observations on the effect of tilting and anxiety. J. Clin. Invest., 1949, 28, 1163.

8. Hickam, J. B., and Frayser, R., Spectrophotometric determination of blood oxygen content. J. Biol. Chem., 1949, 180, 457.

9. Van Slyke, D. D., and Neill, J. M., The determination of gases in blood and other solutions by vacuum extraction and manometric measurement. J. Biol. Chem., 1924, 61, 523.

10. Nelson, N., A photometric adaptation of the Somogyi method for the determination of glucose. J. Biol. Chem., 1944, 153, 375.

11. Stead, E. A., Jr., Warren, J. V., and Brannon, E. S., Cardiac output in congestive heart failure. Am. Heart J., 1948, 35, 529.

12. Bertrand, J., Delay, J., and Guillain, J., L'électroencéphalogramme dans le myxoedème. Compt. rend. Soc. de biol., 1938, 129, 395.

13. Tanner, J. M., The construction of normal standards for cardiac output in man. J. Clin. Invest., 1949, 28, 567.

14. Scheinberg, P., Cerebral blood flow in vascular disease of the brain, with observations on the effects of stellate ganglion block. Am. J. Med., 1950, 8, 139.

15. Stewart, H. J., and Evans, W. F., Peripheral blood flow in myxedema. Arch. Int. Med., 1942, 69, 808.

16. Abramson, D. I., Vascular Responses in the Extremities of Man in Health and Disease. Univ. of Chicago Press, Chicago, Ill., 1944, p. 264.

17. Kety, S. S., Hafkenschiel, J. H., Jeffers, W. A., Leopold, I. H., and Shenkin, H. A., The blood flow, vascular resistance, and oxygen consumption of the brain in essential hypertension. J. Clin. Invest., 1948, 27, 511.

18. Scheinberg, $P$., The cerebral circulation in heart failure. Am. J. Med., 1950, 8, 148.

19. Scheinberg, P., Cerebral blood flow and metabolism in pernicious anemia. Blood, in press. 
20. Kety, S. S., and Schmidt, C. F., The effects of active and passive hyperventilation on cerebral blood flow, cerebral oxygen consumption, cardiac output, and blood pressure of normal young men. J. Clin. Invest., 1946, 25, 107.

21. Scheinberg, $P$., Unpublished observations.

22. Himwich, W. A., Homburger, E., Maresca, R., and Himwich, H. E., Brain metabolism in man: Unanesthetized and in pentothal narcosis. Am. J. Psychiat., 1947, 103, 689.
23. Kety, S. S., and Schmidt, C. F., The effects of altered arterial tensions of carbon dioxide and oxygen on cerebral blood flow and cerebral oxygen consumption of normal young men. J. Clin. Invest., 1948, 27, 484.

24. Kety, S. S., Lukens, F. D. W., Woodford, R. B., Harmel, M. H., Freyhan, F. A., and Schmidt, C. F., The effects of insulin hypoglycemia and coma on human cerebral metabolism and blood flow. Fedderation Proc., 1948, 7, 64.

\section{NOTIFICATION TO SUBSCRIBERS \\ FOR CHANGES IN RATES FOR 1951 NEW AND RENEWAL SUBSCRIPTIONS}

Effective October 1, 1950, new and renewal orders for Volume 30,1951 , will be $\$ 12.00$ (payable in U. S. funds), instead of $\$ 10.00$. Subscriptions are on a January through December or July through June basis.

Special rate for medical students, interns, residents and felwill be $\$ 6.00$ instead of $\$ 5.00$ as formerly.

Vols. 1-11, inc. (1924-1932) - Special Sales Price, while available, \$25.00. Vol. 12 (1933) through Vol. 29 (1950), \$10.00 a volume.

All single copies from Vol. 1, No. 1 through Vol. 28, No. 6, $\$ 2.00$ each. Vol. 29 (1950), No. 1, on $-\$ 1.50$ each. 